Brit.J.Sports Med.: 1979, 13, 81-83

\title{
THE CHARACTERISTICS OF A LOW RESISTANCE BREATHING VALVE DESIGNED FOR THE MEASUREMENT OF HIGH AEROBIC CAPACITY
}

\author{
P. JAKEMAN, BSc, MSc and B. DAVIES, PhD
}

Human Performance Laboratory, University of Salford, England

\section{INTRODUCTION}

The study of physical performance capacity has been of particular interest to the exercise physiologist and many accurate techniques have been designed for the measurement of human performance. The use of maximal oxygen uptake has, since its development by Hill et al in 1924 , been regarded as a valuable measure of cardiorespiratory function and used extensively as a criterion of performance capacity of endurance athletes (e.g. Taylor et al, 1955; Saltin and Åstrand, 1967; Hanson, 1973).

The measurement of maximal oxygen uptake is not normally limited by pulmonary ventilation as it is recognised that as oxygen uptake reaches a plateau, ventilation continues to increase, often in excess of $\mathbf{2 0 0}$ L.min ${ }^{-1}$ during heavy exercise (Asmussen and Nielsen, 1946). However, it has recently been shown that a reduction in $\mathrm{VO}_{2}$ max and endurance capacity may result if ventilation is impeded by external airway resistance (Ceretelli et al, 1969; Dressendorfer et al, 1977). These studies suggest that when a high resistance is introduced into the breathing circuit, volitional fatigue may occur before oxygen transport to the active muscle or anaerobic metabolism become limiting factors. The use of a low resistance breathing circuit is thus essential in the measurement of maximal oxygen capacity.

The World Health Organisation (Andersen et al, 1971) recommend that for the purpose of collecting respiratory gases, a low resistance breathing valve (less than $5 \mathrm{~cm} \mathrm{H}_{2} \mathrm{O}$ at 300 L. $\mathrm{min}^{-1}$ ) be used, coupled to a gas line collection system not exceeding $1.5 \mathrm{~cm} \mathrm{H} \mathrm{H}_{2} \mathrm{O}$ at 200 L. $\mathrm{min}^{-1}$. These conditions were based on measurement of intermittent air flow during heavy exercise which may exceed 350 L. $\mathrm{min}^{-1}$ at peak flows. One of the most commonly used breathing valves is the Otis McKerrow, which, although fulfilling the requirements of WHO, is cumbersome and requires a gantry support to ensure an efficient seal at the mouth. In addition, it tends to cause chaffing of the gums at high metabolic work loads, and is relatively expensive.

The specifications of the Salford HPL breathing valve described in this report are well within those recommended by the WHO publication. Furthermore, the valve is lightweight and the design facilitates minimum irritation at the mouth at maximum metabolic work levels. These features make it very acceptable to the high-level performer.

\section{VALVE SPECIFICATIONS}

Essentially the valve is made from lightweight perspex tubing (Manchester Plastics Ltd.) into which are mounted two rubber flap one-way low resistance valves (Mine Safety Appliances Ltd.). The clear perspex tubing is turned to size so as to accommodate the valve seatings and ensure unobstructed movement of the rubber flaps at maximum flow (figure 1). The ' $T$ ' shape of the valve assembly is the most successful and the simplest design and is currently employed in the Triple ' $\mathrm{J}$ ' (Collins, Mass.), Daniels (Daniels, 1971) and Max Planck breathing valves. All joints in the perspex assembly are carefully sealed using chloroform, which dissolves the perspex on contact and dries to a strong neat joint. The inner rubber flaps of the valves are easily removed and replaced should they become worn or damaged.

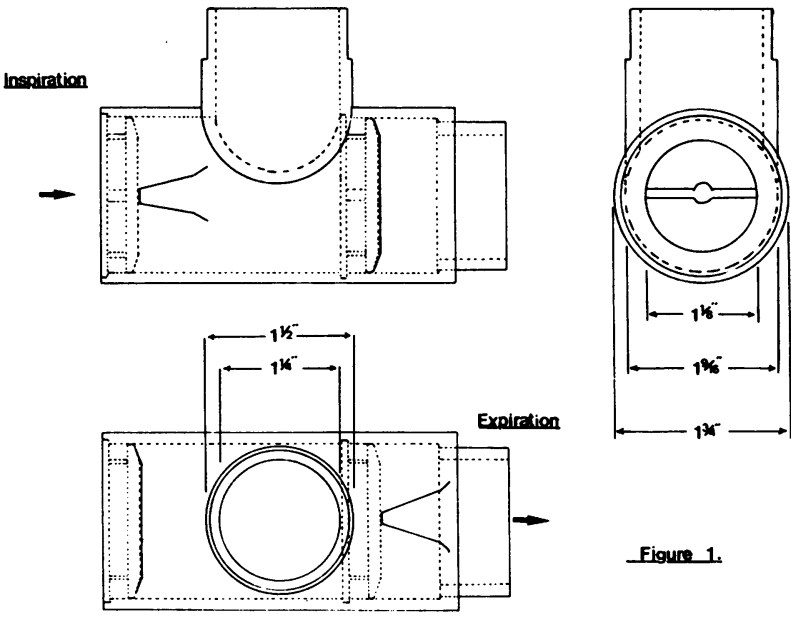

The total weight of the valve is $65 \mathrm{~g}$ and the dead space volume, including the breathing port, amounts to $80 \mathrm{ml}$. The corresponding figures for the Otis McKerrow breathing valve are $350 \mathrm{~g}$ and $210 \mathrm{ml}$ respectively. The use of a large, broad flanged rubber mouthpiece (Collins, Mass.) enabled the valve to be used without any additional support in the majority of subjects tested. In cases where further support was necessary an expandable 
rubber headstrap was used. The expired gases were removed through lightweight 11/2" 'Falconia' tubing (Baxter, Woodhouse and Taylor Ltd.) coupled to the expiratory port and sealed to atmospheric air by a short length of water-resistant adhesive tape.

The air flow characteristics of the Salford HPL, Otis McKerrow and Max Planck valves were analysed simultaneously under standardised conditions.

Resistance to air flow was measured using a water manometer connected firstly across the inspiratory port and the breathing port, and secondly across the breathing port and the expiratory port. Resistance to flow, defined as the pressure drops across the two ports, and expressed in $\mathrm{cm}$ of $\mathrm{H}_{2} \mathrm{O}$, was measured for a constant flow of air over the range 0-336 L.min ${ }^{-1}$. The air flow was supplied from a compressor, controlled and accurately measured by passing through a large-bore rotameter. The results presented along with similar measurements on the remaining equipment used in the gas collection system (figure 2, Table I), emphasise the extremely low resistance values (less than $3 \mathrm{~cm}$ of $\mathrm{H}_{2} \mathrm{O}$ across the inspiratory port and $1 \mathrm{~cm} \mathrm{H} \mathrm{H}_{2} \mathrm{O}$ across the expiratory port at 300 L.min ${ }^{-1}$ ) of this breathing valve.

\section{DISCUSSION}

The breathing valve described in this report has been used extensively in our laboratory for the last six months. The versatility of such a lightweight and efficient component has been highlighted by its use at two extreme measures of physical performance capacity.

At the one extreme, in the monitoring of world-class athletes, the low resistance has minimised the amount of discomfort experienced when ventilation, through what amounts to an unnaturally narrow aperture, approaches or exceeds 200 L. $\mathrm{min}^{-1}$. This, plus the absence of any separate physical support for the valve, has been conducive to reproducible, high level test performances.

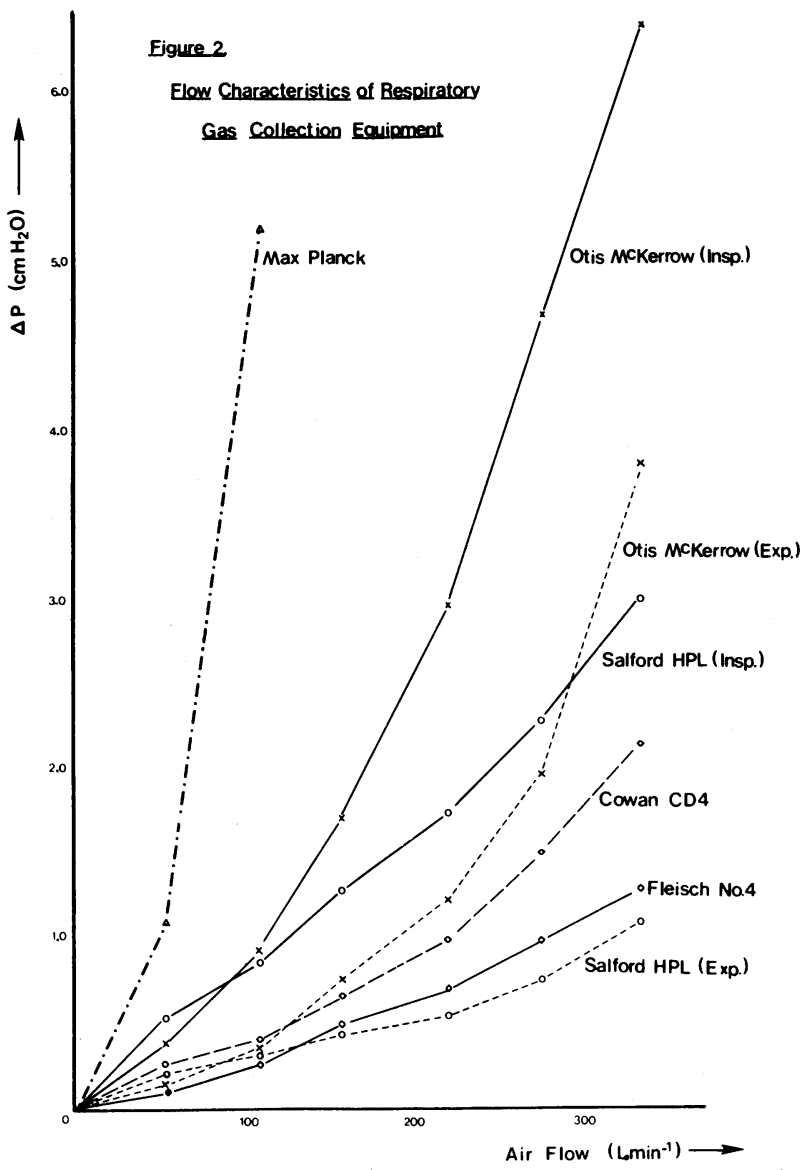

At the other extreme, the 'insignificance' of the valve contributed to the successful measurement of aerobic capacity in spina-bifida children - a group who have a natural 'phobia' to complicated breathing attachments and who possess only a fraction of the functional capacity of champion athletes.

TABLE I

Flow characteristics of respiratory gas collection equipment

$\Delta \mathrm{P}\left(\mathbf{c m ~ H} \mathrm{H}_{2} \mathrm{O}\right)$

\begin{tabular}{|c|c|c|c|c|c|c|c|}
\hline $\begin{array}{l}\text { Flow } \\
\text { L.min }\end{array}$ & $\begin{array}{l}\text { Parkinson } \\
\text { Cowan }\end{array}$ & $\begin{array}{l}\text { Fleisch No.4 } \\
\text { Pneumotach }\end{array}$ & $\begin{array}{l}\text { Otis } \\
\text { (insp) }\end{array}$ & $\begin{array}{l}\text { Otis } \\
\text { (exp) }\end{array}$ & $\begin{array}{l}\text { Salford } \\
\text { (insp) }\end{array}$ & $\begin{array}{l}P L \\
\text { (exp) }\end{array}$ & $\begin{array}{l}\text { Max } \\
\text { Planck }\end{array}$ \\
\hline 56 & 0.22 & 0.10 & 0.33 & 0.13 & 0.55 & 0.18 & 1.10 \\
\hline 112 & 0.35 & 0.27 & 0.88 & 0.35 & 0.86 & 0.31 & 5.25 \\
\hline 168 & 0.66 & 0.48 & 1.72 & 0.74 & 1.27 & 0.44 & $>10$ \\
\hline 224 & 1.01 & 0.71 & 2.94 & 1.22 & 1.77 & 0.57 & \\
\hline 280 & 1.52 & 0.99 & 4.77 & 1.94 & 2.28 & 0.76 & \\
\hline 336 & 2.15 & 1.30 & 6.40 & 3.80 & 3.04 & 1.10 & \\
\hline
\end{tabular}


We would like to re-emphasise the WHO's recommendation of the standardisation of procedures and methods used in the measurement of physical performance capacity. It is recognised that although the main principles for measuring maximal oxygen uptake remain unchanged, there are still a number of theoretical and methodological problems to be solved. The particular methodological problem outlined in this report, may well be one of the factors contributing to the consider- able variations in $\mathrm{VO}_{2}$ max values reported by different groups of workers in the field of human performance and sports science.

\section{ACKNOWLEDGEMENT}

P. Jakeman is supported by a Provincial Insurance Company research scholarship.

\section{REFERENCES}

Andersen, K. L., Shephard, R. J., Denolin, H., Varnauskas, E. and Masironi, R. 1971 "Fundamentals of Exercise Testing", World Health Organisation, Geneva.

Asmussen, E. and Nielsen, M. 1946 "Studies on the regulation of respiration in heavy work", Acta Physiol.Scand. 12, 171-188.

Cerretelli, P., Sikano, R. S. and Farhi, L. E. 1969 "Effect of increased airway resistance in ventilation and gas exchange during exercise", J.Appl.Physiol. 27, 597-600.

Daniels, J. T. 1971 "Portable respiratory gas collection equipment", J.Appl.Physiol. 31, 164-167.

Dressendorfer, R. H., Wade, C. E. and Bernauer, E. M. 1977 "Combined effects of breathing resistance and hyperoxia on aerobic work tolerance", J.Appl.Physiol. 42, 444-448.

Hanson, J. 1973 “Maximal exercise performance in members of the US Nordic Ski Team”, J.Appl.Physiol. 35, 592-595.

Hill, A. V., Long, C. N. H. and Lupton, H. 1924 "Muscular exercise and oxygen uptake", Proc.Roy.Soc.London, Ser.B. 97, 155-176.

Saltin, B. and Åstrand, P-O. 1967 "Maximal oxygen uptake in athletes", J.Appl.Physiol. 23, 353-358.

Taylor, H. L., Buskirk, E. and Henshel, A. 1955 "Maximal oxygen intake as an objective measure of cardiorespiratory fitness", J.Appl.Physiol. 8, 73-80. 